\title{
ANTHROPOLOGICAL QUESTS IN ARCHITECTURE: PURSUING THE HUMAN SUBJECT
}

\author{
Hedda Haugen Askland*, Ramsey Awad, Justine Chambers, Michael Chapman \\ The University of Newcastle \\ Hedda.Askland@newcastle.edu.au
}

\begin{abstract}
In this paper, we explore what architectural practice and, more specifically, the architectural research domain, may gain from the theoretical and methodological premise of anthropology and ethnography. The paper explores a historical link between anthropology and architecture as academic disciplines, arguing that the disciplines are aligned through anthropology's search for understanding the conditions of humanity and architecture's role in forming these very conditions. We do not intend to explicate the individual disciplines but are interested in the crossover between the two and, more specifically, what insights anthropology and ethnography may offer to the discipline of architecture. We consider the relationship between anthropology and architecture, as both a research domain and a profession, and question how anthropology-as an approach to research more so than a discipline-can contribute to the advancement of architectural practice and research.
\end{abstract}

Keywords: Architecture; Anthropology; Design practice; Design research; Research methods.

\section{INTRODUCTION}

As a dynamic discipline, architecture is an ever-changing practice that responds to the cultural, social, political and financial circumstances of which it is part. At different historical periods, architecture - as both art and practice-will manifest a particular pattern that reflects a reciprocal relationship between the discipline as a social agent and society itself. In the era between the world wars, for example, the rise of modernism led to changes in the way that architecture was practiced and to the architecture that was created; that is, it led to changes both in terms of how architecture was made and what was made (Cesal, 2010). Similarly, the postmodern movement as a societal process led to changes in architectural expressions and practices. It energised new questions about epistemology, ethics and the politics of architecture, subsequently resulting in ground breaking architectural expressions such as the Neue Staatsgalerie in Stuttgart, Germany, and the EMP Museum in Seattle, USA. Gauging the cultural relevance of architectural ideas and expressions has always been an intuitive part of the profession, however, until the end of the last century, critical engagement with academic discourses, theories and methods rarely supported such processes (Clarke, 2011a; Suri, 2011). There is today a growing recognition within the architecture and design community that a more detailed understanding of the cultural, creative and aspirational values that structure the profession and the role this plays for productivity, commercial viability and innovation is required in the move towards disciplinary creativity and innovation. Upon recognition of the fact that '[c]ontemporary design [...] is as much about the spaces, interactions, and meanings between things and people as it is about things themselves' (Clarke, 2011a, p. 9), architects are increasingly turning to social science theory to seek relevance and impact of ideas.

The synthesis of architecture and social science has come together in the nascent discipline of design anthropology (e.g. Clarke, 2011b), which represents a merging of the academic discipline of anthropology with the profession of design. Essentially, design anthropology is an approach to design and architecture that seeks to understand how design 
forms part of defining what it means to be human, the diversity of human values, and the transformation of such values into tangible experiences. Placing a focus on watching, noticing, and learning about people, places and artefacts (Suri, 2011), it represents a designerly shift towards cultural sensitivity that is believed to support a move towards socially responsive design; an approach that 'takes into account "soft" factors such as notions of pollution, sacredness, humility, and modesty' (Clarke, 2011a, p. 10-11). As such, it represents as much a methodology as a discourse; it is a method that supports designers in their search for patterns and hidden rules, for generating a sense of future orientation and making strategic judgements about the relevance and meaning of design (Suri, 2011).

Referring to the changing economical conditions of design and innovation, Halse (2008, p. 1) explains that:

[d]evelopments in the global relations of production and consumption have led companies [...] to look for new business opportunities based on the creative potential residing with their users and the everyday practice of these. These two developments in design and business signal a readiness for actively including users and images of their practice as valuable contributions in the design process. Anthropological competences are increasingly called for in this ongoing reformulation of design, which intersects the categories of production and consumption.

According to Halse (2008), anthropology represents a vital resource for facilitating exchange between the various sites of use, business and design. The link between anthropology and architecture is not new, with a particular association between architecture and ethnography, the key method of anthropology. In anthropology, ethnography is a well-established method of data collection. It encapsulates at the same time a methodology and an epistemology; it refers to a family of qualitative methods that involve direct and sustained contact with human agents, such as participant observation and interviews, and to a particular approach to knowledge that reflects the philosophical position of social constructivism and phenomenology. It is an approach that perceives human beings as both objects and subjects, that emphasises the dynamic relationship between the researcher and those that are being studied and the role of the researcher's self, and that leads to rich, written accounts that emphasise the irreducibility of human experience. It is generally small-scale and focuses on rich, deep data rather than broad, quantifiable facts, and it is up to the ethnographer's discretion whether or not to consider historical and/or macro factors and engage in a critical cultural/political discourse (O'Reilly, 2009).

In architecture, on the other hand, ethnography is less defined and, as McGowan (2011, p. 8) proclaims, 'the role of fieldwork [ethnography] in the present is still negotiable.' Whilst negotiable and ambiguous, ethnography in architecture has been summarised by Ewing (2011a, p. 5) as

tacit design knowledge, a resource for the study of site and the making of projects, enacted by learnt strategies, techniques and skills, rather than disciplinary-drive models of applied methods or articulated methodologies.

Ethnography, thus, takes on quite a different meaning within the discipline of architecture compared to anthropology. Focussing on the ethnographic tradition of inhabiting and writing about the field, ethnographic approaches may, however, as McGowan (2011, p. 8) asserts, 'be used in architecture as a method of observation, data acquisition and representation; a way of interacting with, documenting and responding to a specific people, time, place and circumstance.' In this paper, we explore what architectural practice and, more specifically, the architectural research domain, may gain from anthropology and ethnography and why there is a natural link between anthropology and architecture as academic disciplines. Through consideration of the historical and philosophical alignment of architecture and anthropology, we consider the relationship between anthropology and architecture, as both a research domain and a profession, 
and question how anthropology - as an approach to research more so than a discipline-can contribute to the advancement of architectural practice and research.

\section{ANTHROPOLOGY AND ARCHITECTURE: \\ EXPLORING CONDITIONS OF HUMANITY - FORMING CONDITIONS FOR HUMANITY}

As a discipline, anthropology is guided by a moral ethos-or political purpose - to 'rediscover the humanity in the peripheral subjects' (Westbrook, 2008, p. 11). It is the science about human diversity, essentially concerned in the ontological idea of 'being'. Most anthropologists promote the view of humans and the world as being co-constituted. The concepts of self and person are largely seen as cultural or social constructions; rather than there being an essential, preordained concept of personhood, religion, law, custom, kinship systems, rituals and everyday living determine who we are and how we see ourselves (e.g. Mauss, 1985; Geertz, 1973). These cultural elements provide insight into the notion of personhood within individual societies and delineate a set of possible social roles and statuses for those who reside within them. As Meyer Fortes (1987, p. 251) notes:

the distinctive qualities, capacities and roles a society endows a person enable the person to be known to be and show him to be the person he is supposed to be.

Rejecting positivist notions of the social world, anthropological analysis looks closely at people's everyday lives and interrogates the habitual, customary and routine. Rather than writing from a preconceived determination of culture, ethnography and other qualitative research methods reconsider how members of a certain community or social group act, feel, interpret the world and understand social behaviour (Spradley, 1979). Emphasising the immersion of the field researcher in a particular socio-cultural context over an extensive period of time, the anthropologist attempts to provide a holistic, culturally relativist interpretation of human interaction through rich and detailed field observations (Geertz, 1973). Providing descriptive, rather than prescriptive, accounts, the anthropologist takes a cultural relativistic stance, attempting to understand the type of socio-cognitive interactions that take place within everyday life from the point of the people studies. As such, anthropology seeks an emic understanding; that is, an understanding of the people studied on their terms (Maykut \& Morehouse, 1994).

Whereas anthropology seeks to understand what it means to be human, architecture provides conditions for being human and responds to the human condition. Exploring the architectural conditions that support and form part of socio-cultural structures have always formed part of ethnographic inquiry, though recent decades have seen a proliferation of ethnographic research (e.g. Carsten \& Hugh-Jones, 1995; Fox, 1993; Waterson, 1990) that illustrate how architectural forms and their configuration represent enduring and significant repositories of knowledge and cultural meaning (McWilliams, 2005, p. 29). Anthropologists have been interested in the affective attachments that link people to place, the ways rooms, buildings and land are endowed with emotional meaning, and the aspects of individual identity that have a desire for, memory of, and emotional attachment to, a physical setting (Hochschild, 2010; Milligan, 2003). The link between architecture and anthropology is, however, not singular and there has been a mutual interest of anthropological discourses within architectural domains. Much of the material that is available to an architect or designer is, essentially, social (Bucciarelli, 1994), and architectural research naturally links with the anthropological concepts of culture and social practice (e.g. Owen, 2008; Shakur et al., 2012). The anthropological interest in, knowledge of, and methods for understanding the social may, thus represent a vital tool for architectural practitioners. Possibly, for this reason, ethnography has been a recurring theme in methodological approaches to architectural history and, in the period since the Second World War, been widely appropriated in architectural discourse.

In the contemporary environment, anthropological theory and ethnographic methods may support architects experimenting with provocative conceptions of design. One of the leaders of the global movement in architecture, Aaron Betsky (2008), for example, argues for a more 
dynamic approach to design that places its emphasis on thinking and arguing over constructing. He challenges architects to experiment questioning how we feel at home in the world, to criticise and engage in taken for granted assumptions. Others, such as the Director of the $13^{\text {th }}$ International Biennale di Venezia, David Chipperfield, provokes the architectural profession to reimagine the possibilities of architecture, 'both as individual acts and as part of a greater vision' (Chipperfield, 2012, no p.). He invites dialogue, debate and opinion, forwarding 'an opportunity to reflect on the discipline of architecture' (Chipperfield, 2012, no p.) for the industry to reimagine itself. Similarly, reflecting what has been perceived as a 'crisis of identity' within the discipline, the President of the $13^{\text {th }}$ International Architecture Exhibition, Paolo Baratta (2012, no p.), calls for a consideration of the fact 'that something different is possible, that we are not condemned to passive acceptance.'

Within the crisis of identity, architectural education, research and artistic production has increasingly experimented with modes of ethnographic exploration. An example of such experimentation can be found in Al-Maimani, Salama and Fadli's paper on the socio-spatial aspects of traditional souqs in the Arabian Peninsula (2014). Whereas Al-Maimani and her colleagues do not mention the words ethnography and anthropology, their research adopts typical ethnographic elements, such as detailed observation of space and behaviour related to spatial, historical and cultural contexts. In the paper, they develop an experiential walkthrough assessment of selected marked spaces within the Souq Mutrah and examines their spatial and socio-cultural aspects through systematic and strategic observation and behavioural mapping. The authors show some ethnographic tendencies in their search for detailed, location-based observations of human behaviour and movement. Despite these tendencies, however, the ethnographic potential of this project remains underutilised and the authors' search for in-depth understanding of movement and activity is restricted to the level of what is happening and how this can be understood in spatial and historical terms. The authors adopt elements of quantitative mapping that allows scoring of the different spaces and their associated activities and behaviours. From this they reveal valuable insights into the spatial and cultural environments of the souq that can support its future development and preservation. The structured and quantitative nature of the observations is, however, limited in its ability to foster understandings of the underpinning and less overt dynamics that form part of people's movement in localised space. Such understanding could be advanced by further embracing the ethnographic elements of the research and include more unstructured observation and positioning the researcher as a participant observer within the spaces. Al-Maimani and her colleagues $(2014,57)$ dismiss such observation as it 'may result in inadequate findings that may reveal only what seems to be already obvious'. In contrast, we would argue that it is indeed through such observations and engagement with the field that the less obvious spatial and socio-cultural aspects that guide people's behaviour can be revealed.

We acknowledge that the ethnographic potential embedded in Al-Maimani et al.'s (2014) study is beyond the scope of their research. When discussed here, it is with the intention of illustrating how architectural research is engaging with ethnographic topics that may be beyond the traditional architectural domain. There is an increased recognition of the potential of ethnography in architectural research and practice. Architect Suzanne Ewing (2011b, p. 309) calls this the 'ethnographic turn' and argues that 'it has affected, and is unsettling architecture's understanding of its own domain, scope, limit, habits, practices, potential and trajectory'. According to Ewing (2011b), fieldwork in architecture will always, unlike other disciplines, contribute and connect, "whether closely or more indirectly or collaboratively, to a form of architectural production, rather than remaining autonomous as field data'. Ethnography in this sense addresses what has often been articulated as 'a gulf to be bridged between observations and interventions' (Halse, 2008, p. iv), moving anthropology's emphasis on descriptive practices towards architecture's more prescriptive practices. It reinterprets the ethnographic field as a field that is not only subject to inquiry but may also be an object of inquiry seeking a service. Here, 
ethnography becomes a hybrid approach that 'actively combines insights and practices from both design and anthropology' (Halse, 2008, p. 1).

The discourse of ethnography in architecture is, however, not restricted to this more applied approach. Henry Glassie, for example, forwards the use of more traditional ethnographic study to expand current understandings of humankind, values, community and history with the aim of attaining a 'more comprehensive definition of architecture' (Glassie, 2000, p. 69). He posits:

[a]ll architects are born into architectural environments that condition their notions of beauty and bodily comfort and social propriety. Before they have been burdened with knowledge about architecture, their eyes have seen, their fingers have touched, their minds have inquired into the wholeness of their scenes. They have begun collecting scraps of experience without regard to the segregation of facts by logical class. Released from the hug of pleasure and nurture, they have toddled into space, learning to dwell, to feel at home. Those first acts of occupation deposit a core of connection in the memory (Glassie, 2000, p. 17).

The cultural conditioning of architects and their practice have been explored in studies such as Robert Venturi, Denise Scott-Brown and Steven Izenour's Learning from Las Vegas (1977), Judith Blau's Architects and Firms (1984), and Edward Robbins' Why Architects Draw (1994). Each of these studies uses anthropological methods and relate to anthropological theory about practice, structure, power and embodiment. Over the past two decades, researchers and designers in the field of Human-Computer Interaction $(\mathrm{HCl})$ have also looked to the discipline of anthropology and the insights triggered by ethnographic analysis. Traditional design methodologies, such as attitude surveys, focus groups and telephone interviews, have accordingly lost their hegemonic influence on design research, and ethnographically informed design practice has attained a permanent place in $\mathrm{HCl}$ research due to its suitability to inform design of new products and interactive solutions (e.g. Blomberg \& Burrell, 2009).

As is suggested by the above, ethnography attains different roles in relation to architecture. It represents both a means and an end for the architectural profession. On the one hand, it can be used by representatives of the architectural profession to understand the field in which they are working; it can be used as a method to seek the relevance and impact of ideas, and as a way to attain a holistic perspective of the local (social, cultural, political, financial, etc.) conditions in which future architectural expressions are to be situated. As such, it supports architects in the identification of the social material of their practice, and, at the disciplinary level, it provides a method and theory for thinking and questioning that can support the discipline in its ever-present need to reimagine itself. On the other hand, ethnography can be seen as an end in itself, by which its role is to generate rich descriptions of architectural practice and, subsequently, support both internal and more wide reaching calls to understand the architectural profession and identify the issues that both affect and condition it. This latter role will be at the centre of the remainder of this paper.

\section{ETHNOGRAPHY: INVESTIGATING WHAT AFFECTS AND CONDITIONS ARCHITECTURAL PRACTICE}

The ethnographic approach adopted from anthropology provides a unique perspective into, for example, the cultural and managerial structure of contemporary practice. There is a dearth of research integrating such an approach and understanding of practice and management within the wider architecture profession. Indeed, where the object of analysis has remained fixed on design, the built environment and the professional product, the analysis of architects and architectural practice and managerialist orientation as objects of inquiry remain limited. This does not suggest that studies that explore (everyday) design practice do not exist. In conjunction to the studies mentioned in the previous section, research has been conducted at institutions such as Palo Alto Research Centre (PARC) and Xerox that explore users' work practices and the ways design 
technologies support work activities (Blomberg 1987, 1988; Blomberg, Giacomi, Mosher, \& Swenton-Well, 1993). Aimed at transforming current design practices within Xerox to promote a more participatory product process, Blomberg and her colleagues (1993, p. 148) write that ethnographic fieldwork provided the study with 'an opportunity for continued involvement of users in the design process and for design iteration in relation to actual situations of use'. According to them, through the use of ethnographic research techniques such as open-ended interviews, observation and video analysis, designers at Xerox were able to develop 'a deeper understanding of use work practices and to provide a context for designers to collaborate with users of the design of new technologies' (Blomberg et al. 1993, p. 151). Similarly, Robert Anderson (1994, p. 179) found in his study of systems design that 'analytical ethnographies can make a contribution to design that may deliberately question conventional frames of reference' and, in doing so, 'they may well bring novel and deep possibilities to light'. Anderson (1994, p. 179) further argues that ethnography may 'offer sensibilities that will cause designers to question the presuppositions of their conventional outlooks' rather than simply 'providing more gist to the mill of conventional design solutions'.

Yet other studies exist that not only emphasise the role of anthropological methodology but also illustrate the role that anthropological theory can bring fore. Using fieldwork as their approach, Brown, Kornberger, Clegg and Carter (2010), for example, examine the relations of power that structure the activities and creativity of professionals working in an architecture firm and investigate 'how power relates to the production of creative identities and outcomes' (Brown et al., 2010, p. 526-527). Using the theoretical framework of Foucault, they consider how power is embedded and reified by the social order and design of organisations and their discursive practices, arguing that

the notionally creative work of professional architects - as a unique cultural construction is governed by relations of power to become a disciplined, organized, situated practice subject to routine constraints and characterized by repetition (Brown et al. 2010, p. 527).

An architectural practice is, as an organism, anything but transparent and constitutes a highly competitive and often secretive organisational structure. The design studio in itself is an organisational structure that is based on various and often unstated relationships where the design process is concealed behind layers of social and cultural interaction and in competition with alternative practices against which it competes. Through the use of Foucault's theoretical framework and the anthropological discourse, Brown et al. (2010) are able to dwell into this secretive structure and analyse how discursive practices form 'the instinctively shared calibration points for defining local reality' (Brown et al. 2010, p. 528).

The theoretical and philosophical underpinnings of anthropology presents architecture with vast opportunity to conceptualise, theorise and, ultimately, understand architectural practice. Unlike other commercial fields, architectural practice is distinguished by an emphasis on interpersonal relationships and the emergence of highly idiosyncractic and multifaceted social groups that are governed or restricted by bureaucratic and economic constraints. The cultural conditions of architectural practice are unique to the discipline and are rarely, if ever, transgressed ([reference to be inserted]). As such, the architectural profession and, even more so, architectural practices can be classified as a social group or social groups; what has, ever since anthropology entered the academic research milieu, been the anthropological subject. Within architectural practice there is a microcosm of organisational data that can be distilled through ethnographic models of analysis. Ethnography provides a methodological approach that can support reflections upon the technological, cultural, social and economic forces that are reinventing architectural practice and the design process more generally, and provide a contemporary overview of the broader contextual issues of architecture through a focus on organisation, as a starting point ([reference to be inserted]). 


\section{ANTHROPOLOGICAL OFFERINGS}

So, what is it that anthropology can bring to architecture? In the foreword of the highly inquisitive set of essays, Future Practice: Conversations from the Edge of Architecture (Hyde, 2012), designer Dan Hill (2012, p. 7) writes:

[f]rom within, it is difficult to [...] perceive, and so question, the deeper values, motives, models or possibilities for the profession; hence, many professional bodies tend to be fossilising within the compacting strata or their habits, discourse and silent assumptions.

Anthropology allows for a 'creative disruption' of the discipline, generating debate, hybridity and movement, providing methodological, theoretical and analytical measures to do so. The anthropological method-the ethnographic fieldwork-offers a rich form of dialogue to the architectural profession and 'the transient and ephemeral way in which artifacts, people, ambiences are encountered' (lacucci \& Wagner, 2003, p. 17). Its potential for architecture lies in its ability to analyse people and communities from the inside, and, as Ewing (2011b, p. 310) contends, the inherent aptitude to work '[w]ith the overlooked and understanding the generative potential of carefully crafted observation output which might activate some aspect of the complex condition of the contemporary, contested public urban domain'.

As is implied in the citation by Ewing, anthropology often works with the overlooked. Traditionally, anthropologists worked in geographically remote areas. This legacy has led to the common assumption that anthropology is a study of 'the Other'; the 'Other' being associated with 'the exotic', a people removed from the world of the anthropologist that, most often, live in a closed, uniform and undifferentiated world. The contemporary condition and the emphasis on the analytical paradigm of culture and society as 'contested, temporal and emergent' (Clifford, 1986, p. 19) have, however, challenged such assumptions. Anthropology is increasingly identified by a subject where the whole studied or made manifest [...] is not a reifiable entity, but a space that embraces the process of knowledge production itself' (Hastrup \& Hervik, 1999, p. 2). Ethnography has, accordingly, moved

[f]rom its conventional single-site location, contextualized by macro-constructions of a larger social order, such as the capitalist world system, to multiple sites of observation and participation that cross-cut dichotomies such as the 'local' and the 'global,' and 'lifeworld' and the 'system' (Marcus, 1995, p. 95).

Nonetheless, anthropology and anthropologists remain focussed on subjects that are marginally defined and 'thrives at the margins, where other folks are either inarticulate, outside society's interest, or even oppressed' (Westbrook, 2008, p. 11). Whereas these margins used to be demarcated by geography, they are now socially defined. The anthropological focus on marginal subjects can, and has been, seen as a political project (Westbrook, 2008), something that may potentially support the architectural profession. Within architecture, there are practices that continuously push the boundaries of what is expected, that challenge the ordinary through practice and imagination. In the social field of architecture, these practices will be found at the margins where they balance the roles of insider and outsider. This relates to anthropology, firstly, in its subject matter, and, secondly, in its role. In relation to the subject matter, the historical engagement of anthropology with the marginal subject have led to a wealth of theories and approaches that can be used to explore the being and practice of these organisations (i.e. it is a tool for external investigation and representation of such practices). In relation to the role, on the other hand, the anthropological legacy may provide a springboard for the marginal practices themselves in their balancing act; it can provide theories and tools that can support them in their search for creative, innovative and cutting-edge practice (i.e. it can be used as a tool for internal investigation of how to provoke ideas and identify the impact and relevance of these).

Architecture-as practice and as expression-emerges through the dynamic interrelationship between the discipline (as a social agent or a cohort of social agents) and the 
world of which it is part. Understanding architectural practice and expression requires an understanding of the contemporary condition under which it came to existence; it requires an understanding of the social, cultural, financial and political milieu of which it is part, as well as the contemporary imaginings of the future. The notion of culture is at the centre of all discussions of the contemporary; indeed, as Westbrook (2008, p. 8) asserts, 'in aspect after problematic aspect of our lives, answers are sought, or at least presumed to exist, under the rubric of "culture". This assertion underpins the last observation that we would like to make in relation to what anthropology may offer architecture. Positioned in the midst of and influencing contemporary and future understandings of culture, architecture both embodies and prescribes culture as expressions of social, political and financial forces. As a discipline, anthropology is often perceived as "key to "Culture" (Reddy, 2008, p. 6); it is "charged with operationalizing knowledge about culture' (Reddy, 2008, p. 6) and represents 'an instrument, a stepping stone, the means by which to mobilize Culture' (Reddy, 2008, p. 7). As such, anthropology may-through its theory, approach and method-provide insight into the cultural currents that underpin architectural practice, both in the past and in the present, and it offers an analytical framework in which the cultural influence and relevance of architectural expressions can be explored. It also offers a historical record through a particular way of writing about the contemporary, which promotes rich, detailed descriptions. Ethnographic writing provides the reader with 'thick' (Geertz, 1973) scientific accounts that present a comprehensive description of the phenomena observed and place it within its context. Such accounts have the advantage of creating images of events and people through rich and relevant details, allowing the reader to develop their personal understanding for further knowledge and perception. Moreover, it is often written in a relatively jargon-free manner, which makes the material more accessible than other scientific texts.

Whereas all of this may seem to support the bridge connecting architecture and anthropology, it is important to note that, whilst the disciplines may thematically, theoretically and methodologically support one another, their integration is not without challenges. A drawback to the anthropological approach is the fact that both the inquest into culture and ethnographic writing are very time consuming. Calling for the immersion of the researcher into the research field, ethnographic fieldwork will most commonly last months, if not years, and the writing of ethnographic monographs will often take equally as long. Moreover, ethnographic fieldwork willregardless of how much time is spent in the field-produce huge sets of data, consisting of interview transcripts, field notes, observations, reflections, photographs, video recordings, secondary data and more. But are architects able to conduct anthropological fieldwork in its conventional manner and will such huge data sets be of value to an architect?

Whilst the ethnographic richness of fieldwork data is likely to be useful, its extensive nature may pose a problem to many architectural projects. Working under often-strong constraints in terms of time and money, collecting, analysing and writing up such data may easily exceed the timeline of an architectural project. Simply adopting the anthropological approach may therefore be problematic. Indeed, as Bichard and Gheerawo (2011, p. 54) proclaim, whilst '[t]he longer studies and observational methods of research that ethnography favors can lead to fundamental truths about the way individuals and groups behave', in time-pressured projects 'designers have to deal with shorter time frames and provoke response rather than waiting for interesting behaviour to be revealed'. The time constraints and the restrictions of cost have seen an adaption of traditional ethnographic methods, which has become known as 'rapid ethnography' (Norman, 1999, as cited in Bichard \& Gheerawo, 2011, p. 48). Drawing on the philosophy of anthropological research, this method 'has enabled designers to gain insights into users' activities in daily life but also keep up with the fast paced needs of commercial business practice' and it 'enables designers to gain access to people's worlds and help them to understand their situation' (Bichard \& Gheerawo, 2011, p. 48). As such, it remains close to the anthropological project of understanding practice and perception on people's own terms and it supports architects and designers in their strive for, as Suri $(2011$, p. 32) eloquently acclaims 
a designed world that has meaning beyond the resolution of purely functional needs, one that also has poetry, communicates subtly something that makes sense, not just by fitting in with the culture and environment in which it lives, but by adding a new dimension to it.

\section{CONCLUSION}

We have in this paper aimed to illustrate the historical alignment between architecture and anthropology and the possible contribution that anthropology can make to architectural practice and research. Speaking of the potential contribution that anthropology can make to other disciplines, Westbrook (2008, p. 76) states that 'ethnography can provide intellectual lives outside of anthropology with (1) a viable aesthetic of adventure; (2) a fairly disciplined preoccupation with the imaginary [...]; and, (3) a sense of intellectual play.' By being brought into the architectural field site, anthropologists can help the profession better understand how practices and management styles influence creativity and development.

The study of anthropolgy has direct implications for the practice of architecture, and specifically with the recent focus on programmatic and social, rather than formal or aesthetic discourses for the production of architecture. As contemporary architectural production realligns itself with the reassembled values of modernism from the 1920s, a range of recognised practices have expanded on the anthropological understanding of architecture through a focus on planning and organisation as a primary motive for spatial invention. In the work of OMA, BIG and MVRdV, amongst others, a sensitivity towards the social and human aspects of experience is conspicuous and influential enough to be considered paradigmatic. This reapproporiation of the human subject, at the expense of the detached architectural object, only reinforces the significance of anthropolgy for the theorisation of contemporary architecture, and its continued multi-disciplinary exploration. This is clear not just in the production of architecture over the last decade, but in the restructuring of architectural practice as a unit, framed by social and human conditions.

Qualitative research brings knowledge of opportunities and constraints within the workplace, management styles that both foster or otherwise hinder workplace creativity and professional development. As Blomberg et al. (1993, p. 147) note:

armed with knowledge of user work practices gained through direct observation of users at work, designers are in a much better position to accurately, and more fully, incorporate users' perspectives in the design, with the potential of improving existing products as well as identifying opportunities for new products.

For architecture, the use of ethnography implies a re-evaluation of taken-for-granted practices, norms and management styles, and the way these render behaviour within the firm. Current research on architectural practice lacks the kind of thick description necessary for this reevaluation. Shifting perspective, anthropological analysis can lead architecture towards the edges of the discipline, to question, criticise and overturn the inherited assumptions that have for so long plagued the profession (Hyde, 2012). By becoming an observer of the day-to-day practices, decision-making and consultation that architects engage with everyday within the firm, anthropology can provide clues and insights to suggest, inquire and explore a set of principles to better design practice-to 'back out the cul-de-sac that architecture has partly built' (Hill, 2012, p. $11)$.

This article has not intended to explicate the individual disciplines of architecture and anthropology but rather to illustrate the crossover between the two and, more specifically, what ethnography and anthropological analysis may offer the discipline of architecture. The historical association between the disciplines whereby architecture has formed part of the anthropological project and the anthropological method has been a recurring theme in architectural history provide fertile ground for interdisciplinary collaboration, as well as more solitary disciplinary inquiry. It provides an approach for exploring the architectural profession and its practices as social fields (Bourdieu, 1977), for investigating questions such as: what conditions the architect?; 
what constitutes and generates architectural praxis?; what defines the disciplinary field?; what values guide architectural practice?; how is architectural practice shaped by and, mutually, shaping its social, cultural and political milieu?; how can certain professional codes and practice be organised and institutionalised so as to reproduce particular power relations?; and, so on. Whilst architecture has over the past two decades become increasingly receptive to the insights of ethnographic analysis and cultural theory, the focus has remained on professional conduct and studies of practice remain scarce. Compared to the ever-growing interest in social and ethnographic research of buildings, space and place (e.g. Lineu, 2010), studies that pay attention to architectural practice itself as a unit of study are limited. Ethnographic analysis offers a holistic approach to the whole of the architectural practice and profession. Like vernacular architecture, 'it favors completeness, recognizes diversity and seeks ways to [...] tell better versions of the human story' (Glassie, 2000, p. 21). It is a tool that can be used to 'crack open' the practice of architecture and interrogate its often secretive and opaque organisational structures. Addressing the calls to 'reinvent the discipline' and resolve 'the crisis of identity', anthropology and its associated method of ethnography provide a means of rethinking architectural practice and management, raising important questions about the practice of architecture and how to approach it in the contemporary, rapidly changing, world.

\section{REFERENCES}

Al-Maimani, A., Salama, A.M., \& Fadli, F. (2014). Exploring socio-spatial aspects of traditional souqs: the case of Souq Mutrah, Oman. International Journal of Architectural Research, 8(1), 50-65/

Anderson, R.J. (1994). Representations and requirements: the value of ethnography in system design. Human-Computer Interaction, 9, 151-182.

Baratta, P. (2012). Introduction by the President of la Biennale di Venezia, Paolo Baratta. The Exhibition of Resonances. Biennale Architettura 2012. Available from: http://www.labiennale.org/en/architecture/exhibition/baratta [Accessed 15 December 2012].

Betsky, A. (2008). Out There: Architecture Beyond Building: 11 th International Architecture Exhibition La Biennale di Venezia. New York: Rizzoli, Venice: Marsilio.

Bichard, J., \& Gheraawo R. (2011). The ethnography in design. In A.J. Clarke (Ed.), Design Anthropology. Object Culture in the 21st Century (45-55). Wien, New York: Springer.

Blau, J. (1984). Architects and Firms: A Sociological Perspective on Architectural Practice. Cambridge: MIT Press.

Blomberg, J. (1987). Social interaction and office communication: effects on user's evaluation of new technologies. In R.E. Kraut (Ed.), Technology and the Transformation of White Collar Work (195210). Hillsdale, NJ: Lawrence Erlbaum Associates.

Blomberg, J. (1988). The variable impact of computer technologies on the organization of work activities. In I. Greif (Ed.), Computer Supportive Cooperation Work: A Book of Readings (771-782). San Mateo, CA: Morgan Kaufman.

Blomberg J., \& Burrell, M. (2009). An ethnographic approach to design. In A. Sears \& J.A. Jacko (Eds.), Human-Computer Interaction; Development Process. Hoboken: CRC Press, 71-94.

Blomberg, J., Giacomi, J., Mosher, A., \& Swenton-Well, P. (1993). Ethnographic field methods and their relation to design. In: D. Schuler and A. Namioka, eds. Participatory Design: Principles and Practices (125-155). Hillsdale, NJ: Lawrence Erlbaum Associates.

Bourdieu, P. (1977). An Outline of a Theory of Practice. Cambridge: Cambridge University Press.

Brown, A., Kornberger, M., Clegg, S., \& Carter, C. (2010). 'Invisible walls' and 'silent hierarchies': a case study of power relations in an architecture firm. Human Relations, 63, 515-549.

Bucciarelli, L.L (1994). Designing Engineers. Cambridge, Mass.: MIT Press.

Carsten, J., \& Hugh-Jones, S. (Eds.) (1995). About the House: Lévi-Strauss and Beyond. Cambridge: Cambridge University Press.

Cesal, E.J. (2010). Down Detour Road. An Architect in Search of Practice. Cambridge, Mass. and London: The MIT Press.

Chipperfield, D. Common Ground [online]. Biennale Architettura 2012. Available from: http://www.labiennale.org/en/architecture/exhibition/chipperfield [Accessed 15 December 2012].

Clarke, A.J. (2011a). Introduction. In A.J. Clarke (Ed.), Design Anthropology. Object Culture in the $21^{\text {st }}$ Century (9-13). Wien, New York: Springer. 
Clarke, A.J. (Ed.). (2011b). Design Anthropology. Object Culture in the 21 $1^{\text {st }}$ Century. Wien, New York: Springer.

Clifford, J. (1986). Introduction: partial truths. In J. Clifford \& G.E. Marcus (Eds.), Writing Culture: the Poetics and Politics of Ethnography (1-26). Berkely: university of California Press.

Ewing, S. (2011a). Introduction. In S. Ewing, J.M. McGowan, C. Speed \& V.C. Bernie (Eds.), Architecture and Field/Work (1-6). London and New York: Routledge.

Ewing, S. (2011b). Field/Work. Architectural Research Quarterly, 15, 309-311.

Fortes, M. (1987). Religion, Morality and the Person: Essays on Tallensi Religion. Cambridge: Cambridge University Press.

Fox, J.J. (1993). Comparative perspectives on Austronesian houses: an introductory essay. In J.J. Fox (Ed.), Inside Austronesian Houses: Perspectives on Domestic Designs for Living (1-28). Canberra: ANU.

Geertz, C. (1973). The Interpretation of Cultures: Selected Essays. New York: Basic Books.

Glassie, H.H. (2000). Vernacular Architecture. Bloomington: Indiana University Press.

Halse, J. (2008). Design Anthropology: Borderland Experiments with Participation, Performance and Situated Intervention (Doctoral dissertation). Retrieved from http://nordicom.statsbiblioteket.dk/ncom/en/publications/design-anthropology\%284bc96110-526b11dd-b542-000ea68e967b\%29.html.

Hastrup K., \& Hervik P. (1994). Introduction. In K. Hastrup \& P. Hervik (Eds.), Social Experience and Anthropological Knowledge (1-12). London and New York: Routledge.

Hill, D. (2012). Foreword: Dan Hill. In R. Hyde (Ed.), Future Practice: Conversations from the Edge of Architecture (6-15). New York: Routledge.

Hochschild, T.R. (2010). 'Our club': Place-work and the negotiation of collective belongingness. Journal of Contemporary Ethnography, 39, 619-645.

Hyde, R. (2012). Future Practice: Conversations from the Edge of Architecture. New York: Routledge.

lacucci, G., \& Wagner, A. (2003). Supporting collaboration ubiquitously: an augmented learning environment for architecture students. In K. Kuutti, E.H. Karsten, G. Fitzpatrick, P. Dourish \& K. Schmidt (Eds.), Proceedings of the Eight European Conference on Computer Supported Cooperative Work. ECSCW 2003 (139-158). Helsinki: Kluwer Academic Publisher.

Lineu, C. (2010). Rethinking the Meaning of Place: Conceiving Place in Architecture-Urbanism. Burlington, VT: Ashgate.

Norman, D.A. (1999). Rapid ethnography. In H. Aldersey-Williams, J. Bound \& R. Coleman (Eds.), The Methods Lab: 24-25. London: Design for Ageing Network (DAN) Royal College of Art.

Marcus, G.E. (1995). Ethnography in/of the world system: the emergence of multi-sited ethnography. Annual Review of Anthropology, 24, 95-117.

Mauss, M. (1985). A category of the human mind: the notion of person; the notion of self. In M. Carrithers, S. Collins \& S. Lukes (Eds.), The Category of the Person: Anthropology, Philosophy, History (1-25). Cambridge: Cambridge University Press.

Maykut, P., \& Morehouse, R. (1994). Beginning Qualitative Research. A Philosophical and Practical Guide. London: The Falmer Press.

McGowan, J.M. (2011). Introduction. In S. Ewing, J.M. McGowan, C. Speed \& V.C. Bernie (Eds.), Architecture and Field/Work (7-10). London and New York: Routledge.

McWilliam, A. (2005). Houses of resistance in East Timor: structuring sociality in the new nation. Anthropological Forum: A Journal of Social Anthropology and Comparative Sociology, 15, 27-44.

Milligan, M.J. (2003). Displacement and identity discontinuity: the role of nostalgia in establishing new identity categories. Symbolic Interaction, 26, 381-403.

O'Reilly, K. (2009). Ethnography. London, Thousand Oaks, New Delhi, Singapore: Sage Publications.

Owen, C. (2008). Architecture betweeen the culture-nature dualismo: a case study of Geoffrey Bawa's Kandalama Hotel. Archnet-IJAR, 2(1), 40-56.

Reddy, D.S. (2008). Caught in collaboration. Collaborative Anthropologies, 1, 51-80 [online]. Available from: PMC (US National Library of Medicine National Institutes of Health), http://www.ncbi.nlm.nih.gov/pmc/articles/PMC2854552/pdf/nihms115009.pdf [Accessed 10 September 2012].

Robbins, E. (1994). Why Architects Draw. Cambridge: MIT Press.

Shakur, T., Hafiz, R., Arsian T.V., \& Cahantimur, A. (2012). Economy and culture in transitions: a comparative study of two architectural heritage sites of Bazars and Hans of Bursa and Dhakar. ArchNet-IJAR 6(3), 91-108. 


\section{ArchNet}

Spradley, J.P. (1979). The Ethnographic Interview. New York: Holt, Rinehart and Winston.

Suri, J.F. (2011). Poetic observation: What designers make of what they see. In A.J. Clarke (Ed.), Design Anthropology. Object Culture in the 21st Century (16-32). Wien, New York: Springer.

Venturi, R., Scott-Brown, D., \& Izenour, S. (1977). Learning from Las Vegas: The Forgotten Symbolism of Architectural Form. Cambridge: MIT Press.

Waterson, R. (1990). The Living House: An Anthropology of Architecture in Southeast Asia. Singapore: Oxford Uni. Press.

Westbrook D.A. (2008). Navigators of the Contemporary. Why Ethnography Matters. Chicago and London: The University of Chicago Press

\section{AUTHORS}

\section{Hedda Haugen Askland}

Lecturer

The University of Newcastle, School of Humanities and Social Science

Email address: Hedda.Askland@newcastle.edu.au

\section{Ramsey Awad}

Senior Lecturer

The University of Newcastle, School of Architecture and Built Environment

Email address: Ramsey.Awad@newcastle.edu.au

\section{Justine Chambers}

Research Assistant

The University of Newcastle, School of Architecture and Built Environment

Email address: justine.a.chambers@gmail.com

\section{Michael Chapman}

Senior Lecturer

The University of Newcastle, School of Architecture and Built Environment

Email address: Michael.Chapman@newcastle.edu.au 